\title{
Formulation of Peel-off Gel Mask Containing Mung Bean (Vigna radiata (L.) Wilczek) Extract
}

\author{
Patihul Husni ${ }^{1, *}$, Ella Masliana Dewi ${ }^{2}$ \\ 1. Department of Pharmaceutics and Pharmaceutical Technology, Faculty of Pharmacy, Universitas \\ Padjadjaran, Jatinangor 45363, Indonesia \\ 2. Department of Pharmacy, Politeknik Kesehatan Kementerian Kesehatan RI, Bandung, Indonesia
}

Received : 26 Dec 2018/Revised : 2 Jan 2019/Accepted : 23 May 2019/Published : 13 Jun 2019

\begin{abstract}
Mung bean (Vigna radiata (L.) Wilczek) is one of the plants that rich in antioxidant compound. Antioxidant is a compound that can inhibit the skin aging process because of photoaging. The aim of this study was to formulate peel-off gel mask containing mung bean (Vigna Radiata (L.) Wilczek) extract using polyvinyl alcohol (PVA) as a base of mask and Hydroxy Prophyl Methyl Cellulose (HPMC) as a viscosity increasing agent and to determine the antioxidant activity of the peel-off gel mask. Antioxidant activity was tested using DPPH (1,1-diphenyl-2-pycrilhidrazil) assay. Mung bean was extracted by maceration method using ethanol $96 \%$. The concentration of mung bean extract in the peel-off mask gel was $4 \% \mathrm{w} / \mathrm{w}$ and variant concentration of PVA were $5 \%(\mathrm{~F} 1), 7.5 \%(\mathrm{~F} 2), 10 \%(\mathrm{~F} 3) \mathrm{w} / \mathrm{w}$. The evaluations were organoleptic, $\mathrm{pH}$, viscosity, drying and film forming, and gel spreadness. The study result showed that the organoleptic of the gel was brownish yellow with $\mathrm{pH}$ approximately $6,196-513 \mathrm{cps}$ in viscosity, $0.0646-0.0730 \mathrm{~cm} / \mathrm{g}$ in gel spreadness and 27.6-54.5 second in drying and film forming. F3 containing mung bean extract 4\%, PVA $10 \%$, HPMC $2 \%$, propylene glycol $15 \%$, potassium sorbate $0.2 \%$, olive oil $0.5 \%$, alpha-tocopherol $0.05 \%$ and distilled water ad $100 \% \mathrm{w} / \mathrm{w}$ was the best formula with $\mathrm{IC}_{50}$ value was $85.2793 \mu \mathrm{g} / \mathrm{ml}$ and significantly different than F1 and F2 ( $\mathrm{p}<0.05)$.
\end{abstract}

Keywords: peel-off gel mask, mung bean extract, Vigna radiata (L.) Wilczek, antioxidant

\section{Introduction}

Previous studies have reported that mung bean is one of the plants that rich in antioxidant compound. Flavonoid compounds contained in mung bean, vitexin and isovitexin, have an antioxidant effect [1]. Vitexin inhibits DPPH radicals of approximately $60 \%$ at $100 \mu \mathrm{g} / \mathrm{ml}$ and effectively inhibits UV rays that can stimulate skin cell death $[1,2]$.

The process of skin damage is showed by the appearance of wrinkles caused by free radicals. Skin aging can occur due to photoaging by UV radiation [3, 4]. Skin aging can be caused by UV radiation (photoaging) which trigger in the formation of ROS (Reactive Oxygen Species) free radical on the skin. Free radicals cause oxidative damage to the tissue known as oxidative stress [5, 6]. Antioxidants can be used to protect the skin from the free radical attack so it can inhibit aging process $[7,8]$.

High content of antioxidants in mung bean is potentially to be formulated into peel-off gel mask to protect our skin from UV radiation so it can be novelty of the research to develop new formula of peel-off gel mask containing mung bean extract. The use of mask has many benefits not only refreshing, repairing and tightening of facial skin but also improving blood circulation, stimulating the activity of skin cells, lifting dead skin cells, softening the skin, and providing nutrient on the skin [9]. Peel-off gel mask can be directly removed without rinsing after the mask is dry so it can remove the dead skin cell [10].

\section{Method}

\subsection{Extraction of mung bean}


Maceration was one of the extraction methods [11]. Mung bean was extracted by maceration method using ethanol $96 \% .1000 \mathrm{~g}$ of dried mung bean powder was weighed and extracted in $500 \mathrm{ml}$ of $96 \%$ ethanol for 24 hours then filtered until filtrate is obtained. The treatment was carried out for 2 days. The filtrate was collected and evaporated using a rotary evaporator at temperature of $40-50{ }^{\circ} \mathrm{C}$ until the ethanol extract was $\pm 50 \mathrm{ml}$.

\subsection{Phytochemical screening of mung bean extract}

Tests of Alkaloid, flavonoid, tannin, saponin, triterpenoids and steroid were done to screening phytochemical content [11].

\subsection{Antioxidant activity test of mung bean extract}

Antioxidant activity was tested using DPPH (1,1-diphenyl-2-pycrilhidrazil) method. A stock solution was prepared by carefully weighing $10 \mathrm{mg}$ extract and add methanol p.a until $100 \mathrm{ml}$ in volumetric flask. A series of solutions in variant concentration was prepared $(10 \mu \mathrm{g} / \mathrm{ml}, 20 \mu \mathrm{g} / \mathrm{ml}$, $30 \mu \mathrm{g} / \mathrm{ml}, 40 \mu \mathrm{g} / \mathrm{ml}$, and $50 \mu \mathrm{g} / \mathrm{ml})$ using the stock solution. One $\mathrm{ml}$ of the solutions was added with 2 $\mathrm{ml} \mathrm{DPPH} 50 \mu \mathrm{g} / \mathrm{ml}$ in the test tube and incubated at room temperature and avoid from light. Absorbance of the test solution was measured at maximum wavelength. The absorbance data was used to calculate the inhibition percentage of extract against DPPH free radical using the equation below.

Inhibition percentage $(\%)=\frac{(\text { ㅁ- } \mathrm{-1})}{\text { ㅁ }} \times 100 \%$

$A_{o}$ was absorbance of blank solution while $A_{1}$ was absorbance of test solution. The $\mathrm{IC}_{50}$ (inhibition concentration 50\%) was determined using the linear regression equation $\mathrm{y}=\mathrm{bx}+\mathrm{a}$, where $\mathrm{x}$ is the concentration $(\mu \mathrm{g} / \mathrm{ml})$ and $\mathrm{y}$ is the percentage of inhibition $(\%)[12,13]$.

Determination of the AAI (Antioxidant Activity Index) value was done by calculating the DPPH concentration used in the test $(\mu \mathrm{g} / \mathrm{ml})$ divided by the $\mathrm{IC}_{50}$ value obtained $(\mu \mathrm{g} / \mathrm{ml})$. AAI value $<0.5$ is a weak antioxidant, AAI $>0.5-1$ is a moderate antioxidant, AAI $>1-2$ is a strong antioxidant, and $\mathrm{AAI}>2$ is a very strong antioxidant [14].

\subsection{Formulation of peel-off gel mask}

Formulation of peel-off gel mask containing mung bean extract was prepared using polyvinyl alcohol (PVA) as a base of mask and hydroxypropylmethyl cellulose (HPMC) as a viscosity increasing agent. All formula are listed in Table 1.

\subsection{Preparation of peel-off gel mask}

All ingredients were weighed carefully using analytical balance. The viscous liquid of $\alpha$ tocopherol was mixed with propylene glycol while potassium sorbate dissolved in distilled water. Dispersion of PVA and HPMC was made using distilled water. The ingredients were mixed together with olive oil and mung bean extract in a beaker glass under stirring. Then distilled water was added until $100 \% \mathrm{w} / \mathrm{w}$ total volume.

\subsection{Physical evaluation of peel-off gel mask}

The physical evaluation involved were organoleptic, $\mathrm{pH}$, viscosity, drying and film forming, and gel spreadness [15]. Organoleptic was observed visually, $\mathrm{pH}$ was measured by using $\mathrm{pH}$ meter, and viscosity was determined by using

Table 1. Formula of peel-off gel mask

\begin{tabular}{lcccccc}
\hline Ingredients (\% w/w) & F1 & F2 & F3 & F4 & F5 & F6 \\
\hline Mung Bean Extract & 4 & 4 & 4 & - & - & - \\
PVA & 5 & 7.5 & 10 & 10 & 10 & 10 \\
HPMC & 2 & 2 & 2 & 2 & 2 & 2 \\
Propylene Glycol & 15 & 15 & 15 & 15 & 15 & 15 \\
Potassium Sorbate & 0.2 & 0.2 & 0.2 & 0.2 & 0.2 & 0.2 \\
Olive Oil & 0.5 & 0.5 & 0.5 & 0.5 & 0.5 & - \\
Alpha-tocopherol & 0.05 & 0.05 & 0.05 & 0.05 & - & - \\
Distilled water & until 100 & until 100 & until 100 & until 100 & until 100 & until 100 \\
\hline
\end{tabular}


Viscometer. Drying and film forming test was carried out 48 hours after the preparation of the mask base and formulation of the peel-off face mask. Samples (triplo) containing about $0.7 \mathrm{~g}$ of the base mask were weighed and spread using a brush, over an area of $5.0 \times 2.5 \mathrm{~cm}$ above the glass object or watch glass, forming a homogeneous thin layer of about $1 \mathrm{~mm}$, to mimic the film formed on the face after the use of peel-off mask. Object glass or watch glass was inserted into the oven at $36.5 \pm 2.0$ ${ }^{\circ} \mathrm{C}$ for 1 hour. The preparation was observed every 10 minutes, until the drying process was complete and the film was completely peeled off of the object glass or watch glass [16]. Test of gel spreadness was done as a following procedure. A total of $1 \mathrm{~g}$ of gel mask was placed carefully on a $20 \times 20 \mathrm{~cm}$ glass. Furthermore, it was covered with another glass and placed a weight on glass with a load of 1 g, 2 g, 5 g, 10 g, 15 g, 20 g, and 25 g. Diameter of spreading mask was measured after 1 minute [17].

\subsection{Antioxidant activity test of peel-off gel mask}

Antioxidant activity was tested using DPPH (1,1-diphenyl-2-pycrilhidrazil) method [12, 13]. Procedure of the test was as same as the procedure to determine antioxidant activity of mung bean extract.

\subsection{Data analysis}

Data and statistic analysis were made by using analysis of varians (one way ANOVA). A value of $\mathrm{p}<0.05$ was considered significant statistically.

\section{Results}

\subsection{Extraction of mung bean}

Extraction of 1000 gram of mung bean powder resulted $42.0825 \mathrm{~g}$ viscous greenish brown and characteristic odor extract.

\subsection{Physicochemical screening of mung bean extract}

The result of phytochemical screening tests is listed in Table 2.

Table 2. Phytochemical screening result of mung bean extract

\begin{tabular}{lc}
\hline \multicolumn{1}{c}{ Test } & Result \\
\hline Alkaloid & - \\
Flavonoid & + \\
Steroid & + \\
Saponin & - \\
Tanin & + \\
\hline
\end{tabular}

\subsection{Antioxidant activity test of mung bean extract}

The results of antioxidant testing on mung bean extract proved that mung bean extract had $\mathrm{IC}_{50}=$ $37.205 \mu \mathrm{g} / \mathrm{ml}$.

\subsection{Formulation and preparation of peel-off gel mask}

The organoleptic of peel-off gel mask preparation was homogenous brownish yellow gel and characteristic odor.

\subsection{Physical evaluation of peel-off gel mask}

The result of physical evaluation of peel-off gel mask was shown in Table 3 and Table 4.

\subsection{Antioxidant activity test of peel-off gel mask}

The result of antioxidant activity test was shown in Table 5.

Table 3. Organoleptic and $\mathrm{pH}(\mathrm{n}=3)$

\begin{tabular}{|c|c|c|c|c|c|}
\hline Formula & Color & Odor & Consistency & Homogeneity & $\mathrm{pH}$ \\
\hline F1 & Brownish yellow & Characteristic mung bean odor & Gel & Homogeneous & $6.239 \pm 0.01$ \\
\hline $\mathrm{F} 2$ & Brownish yellow & Characteristic mung bean odor & Gel & Homogeneous & $6.274 \pm 0.02$ \\
\hline F3 & Brownish yellow & Characteristic mung bean odor & Gel & Homogeneous & $6.264 \pm 0.02$ \\
\hline F4 & Clear & Characteristic PVA odor & Gel & Homogeneous & $6.182 \pm 0.01$ \\
\hline F5 & Clear & Characteristic PVA odor & Gel & Homogeneous & $6.138 \pm 0.02$ \\
\hline F6 & Clear & Characteristic PVA odor & Gel & Homogeneous & $6.149 \pm 0.03$ \\
\hline
\end{tabular}


Table 4. Viscosity, gel spreadness and time of drying and film forming $(n=3)$

\begin{tabular}{cccc}
\hline Formula & Viscosity $(\mathrm{Cps})$ & Gel spreadness $(\mathrm{cm} / \mathrm{g})$ & Time of drying and film forming $(\mathrm{Sec})$ \\
\hline F1 & $196.7 \pm 15.3$ & $0.0646 \pm 0.003$ & $54.5 \pm 13.90$ \\
F2 & $330.0 \pm 26.5$ & $0.0727 \pm 0.010$ & $45.3 \pm 0.61$ \\
F3 & $513.3 \pm 35.1$ & $0.0730 \pm 0.009$ & $27.6 \pm 7.40$ \\
F4 & $180.0 \pm 20.0$ & $0.0691 \pm 0.010$ & $25.4 \pm 8.30$ \\
F5 & $200.0 \pm 20.0$ & $0.0825 \pm 0.004$ & $27.1 \pm 10.00$ \\
F6 & $163.3 \pm 15.3$ & $0.0844 \pm 0.006$ & $25.4 \pm 12.70$ \\
\hline
\end{tabular}

Table 5. $\mathrm{IC}_{50}$ and antioxidant activity index (AAI)

\begin{tabular}{cccc}
\hline Formula & $\mathrm{IC}_{50}(\mu \mathrm{g} / \mathrm{ml})$ & Antioxidant activity index (AAI) & Antioxidant properties \\
\hline F3 & 85.4793 & 0.585 & Medium \\
F4 & 105.3105 & 0.475 & Weak \\
F5 & 159.316 & 0.314 & Weak \\
\hline
\end{tabular}

\section{Discussion}

\subsection{Extraction of mung bean}

Extraction of mung bean powder was done by maceration method using ethanol $96 \%$. The method is chosen to avoid damage of active substances due to heating. Ethanol $96 \%$ was used to extract polar substance like flavonoid. Active substances taken from mung bean powder are flavonoids which has an antioxidant effect [2]. The extraction process will produce a liquid extract which is then concentrated by using a rotary evaporator at $40-50{ }^{\circ} \mathrm{C}$. The viscous extract obtained has characteristic odor of mung bean and greenish brown in color. Extraction of 1000 gram of mung bean powder resulted $42.0825 \mathrm{~g}$ $(4.2083 \%)$ viscous extract.

\subsection{Physicochemical screening of mung bean extract}

Phytochemical screening tests include alkaloid, flavonoid, tannin, steroid and saponin tests. Mung bean extract positively contains tannins, flavonoids and steroids. Data are listed in Table 2.

\subsection{Antioxidant activity test of mung bean extract}

Test of antioxidant activity was the main parameter of this research and conducted on mung bean extract using DPPH method. This method was chosen because it was a simple, quick method, using samples and chemicals in small amounts and most commonly used for in vitro antioxidant testing $[12,13]$. The principle of DPPH method is that when the DPPH solution is mixed with a sample that has antioxidant activity, it causes a reduction form with the change of purple to yellow color. The results of antioxidant testing on mung bean extract proved that the $\mathrm{IC}_{50}$ of mung bean extract is 37.205 $\mu \mathrm{g} / \mathrm{ml}$. An antioxidant agent which has high antioxidant activity will have low $\mathrm{IC}_{50}$ value. Mung bean extract was able to inhibit $50 \% \mathrm{DPPH}$ at concentration $37 \mu \mathrm{g} / \mathrm{ml}$. Based on the calculation of the value of AAI (Antioxidant Activity Index), mung bean extract had AAI value 1.34 or a potent antioxidant properties. In this study, quercetin was used as a positive control. The $\mathrm{IC}_{50}$ value was 4.825 $\mu \mathrm{g} / \mathrm{ml}$ which mean quercetin had antioxidant activity stronger than mung bean extract.

\subsection{Formulation and preparation of peel-off gel mask}

The peel-off gel mask was formulated into three variance concentration of PVA. The function of PVA is a film forming agent while the function of HPMC, propylene glycol, potassium sorbate, olive oil, alpha-tocopherol and distilled water is viscosity-increasing agent, humectant agent, antimicrobial preservative, humectant agent, antioxidant agent and solvent, respectively. Based on the calculation using $\mathrm{IC}_{50}$ of mung bean extract, the concentration of mung bean extract used in the peel-off mask gel was $4 \% \mathrm{w} / \mathrm{w}$. Varian of PVA 
concentrations in the formula were $5 \%(\mathrm{~F} 1), 7.5 \%$ (F2), 10\% (F3) w/w. The various concentration of PVA was aimed to get the concentration of PVA resulted the best time of drying and film forming. Formula without mung bean extract, olive oil and alpha-tocopherol was used as a control (F4, F5, F6). The reason of F5 did not contain alpha-tocopherol was to know affect of the alpha-tocopherol on antioxidant activity test result.

\subsection{Physical evaluation of peel-off gel mask}

The physical evaluation of peel-off gel mask were organoleptic, $\mathrm{pH}$, viscosity, drying and film forming, and gel spreadness. Detail of the results was listed in Table 3 and Table 4.

Organoleptic test was carried out to see the physical appearance of the preparation by observing the color, smell, consistency and homogeneity of the preparation. The consistency of all formulas was gel. F1, F2 and F3 were yellowish brown and characteristic odor of mung bean. Whereas F4, F5, and F6, which were control formula and base mask, had the appearance of clear white and PVA odor. Based on the tests performed, all of formulas were a homogeneous preparation. The $\mathrm{pH}$ of gel mask preparations was approximately 6 . The $\mathrm{pH}$ of the gel mask preparations was within the normal $\mathrm{pH}$ range of the skin (4.5-6.5).

The viscosity test was carried out using the DV02 viscometer using a Spindle 2. The results of the viscosity test showed that each formula had different viscosity. There was a difference in the average viscosity value due to the effect of PVA concentration in $\mathrm{F} 1$ to $\mathrm{F} 3$. The higher concentration of PVA was used in the formula, the higher viscosity was obtained. Based on the results of testing the spreadness of gel mask, it was concluded that the increasing of PVA concentration affected the gel spreadness.

Formula without extracts (F4, F5, and F6) were faster in dry time than the other three formula containing extract. The drying test of the film showed that F3 dried faster than F1 and F2, this might be caused by the high concentration of PVA in the formula. The fastest drying time for the film layer was F3 (27.2 minutes). Based on the data obtained only F3 which meets requirement of the drying time of the peel-off gel mask (15-30 minutes) [16]. Analysis of varians (one way ANOVA) were used to analyze data. Based on the physical evaluation, statistic calculation result showed that F3 was significantly different than F1 and F2 $(p<0.05)$.

\subsection{Physical evaluation of peel-off gel mask}

Antioxidant activity tests of the peel-off gel mask containing mung bean extract were performed on F3, F4, and F5. Testing on F4 and F5 was done to determine whether additional ingredients such as $\alpha$-tocopherol and olive oil in the preparation might affect the results of antioxidant activity test. Based on the antioxidant activity test, F3 was the best formula. F3 had an average value of $\mathrm{IC}_{50} 85.4793 \mu \mathrm{g} / \mathrm{ml}$ and had a medium antioxidant properties with an AAI value 0.585.

Average $\mathrm{IC}_{50}$ value of F4 was $105.3105 \mu \mathrm{g} / \mathrm{ml}$ and had a weak antioxidant properties with an AAI value 0.475 while $\mathrm{F} 5$ had an average $\mathrm{IC}_{50}$ value $159.316 \mu \mathrm{g} / \mathrm{ml}$ and had a weak antioxidant properties with an AAI value 0.314. The addition of $\alpha$-tocopherol and olive oil did not affect the antioxidant activity test on peel-off gel mask containing mung bean extract.

\section{Conclusion}

Based on physical evaluation and antioxidant activity, formula containing mung bean extract $4 \%$, PVA $10 \%$, HPMC $2 \%$, propylene glycol $15 \%$, potassium sorbate $0.2 \%$, olive oil $0.5 \%$, alphatocopherol $0.05 \%$ and distilled water ad $100 \% \mathrm{w} / \mathrm{w}$ was the best formula with $\mathrm{IC}_{50}$ value was 85.2793 $\mu \mathrm{g} / \mathrm{ml}$ and significantly different to other formula $(\mathrm{p}<0.05)$.

\section{References}

[1] Cao, D et al, (2011) 'Antioxidant Properties of the Mung Bean Flavonoids on Alleviating Heat Stress', Plos One, 6 (6), pp. 1-9, doi: 10.1371/journal.pone.0021071.

[2] Tang, D., Y.Dong, H. Ren, L. Li, and C. He. (2014) 'A review of phytochemistry, metabolite changes, and medicinal uses of the 
common food mung bean and its sprouts (Vigna radiata (L). R. Wilczek ), Chemistry Central Journal, 8 (4), pp. 1-9, doi: 10.1186/1752-153X-8-4.

[3] D'Orazio, J. Jarrett, S. Amaro-ortiz, A. and Scott T. (2013) 'UV radiation and the skin', International Journal of Molecular Sciences, 14, pp. 12222-12248, doi: 10.3390/ijms140612222.

[4] Puizina-Ivic, N. (2008) 'Skin aging', Acta Dermatoven APA, 17 (2), pp. 47-54.

[5] Masaki, H. (2010) 'Role of antioxidants in the skin: Anti-aging effects', Journal of Dermatological Science, 58 (2), pp. 85-90, doi: 10.1016/j.jdermsci.2010.03.003.

[6] Pham-Huy, L. A., He, H., and Pham-Huy, C. (2008) 'Free radicals, antioxidants in diseases and health', International Journal of Biomedical Sciences', 4 (2), pp. 89-96.

[7] Valko, M et al. (2007) 'Free radicals and antioxidants in normal physiological functions and human disease', The International Journal of Biochemistry \& Cell Biology, 39 (1), pp. 44-84, 10.1016/j.biocel.2006.07.001.

[8] Pandel, R., Poljsak, B., Godic, A., and Dahmane, R. (2013) 'Skin photoaging and the role of antioxidants in its prevention', ISRN Dermatology, pp. 1-11. doi: 10.1155/2013/930164.

[9] Yadav, N., and Yadav, R. (2015) 'Preparation and evaluation of herbal face pack', International Journal of Recent Scientific Research, 6 (5), pp. 4334-4337.

[10] Beringhs, A et al, (2013) 'Green Clay and Aloe Vera Peel-Off Facial Masks: Response Surface Methodology Applied to the Formulation Design', American Association of Pharmaceutical Scientists, 14 (1), pp. 445455, doi: 10.1208/s12249-013-9930-8.

[11] Tiwari,P., Kumar, B., Kaur, M., Kaur, G., Kaur, H. (2011) 'Phytochemical screening and extraction:A Review', International Pharmaceutica Sciencia, 1 (1), pp. 98-106.

[12] Molyneux, P. (2004) 'The use of the stable free radial diphenylpiryl-hydrazil (DPPH) for estimating antioxidant activity,
Songklanarin Journal Science Tecnology, 26 (2), pp.211-219.

[13] Kedare, S.B., and Singh, R.P. (2011) 'Genesis and development of DPPH method of antioxidant assay', J Food Sci Technol, 48 (4), pp. 412-422. doi: 10.1007/s13197-0110251-1.

[14] Vasic, S.M., Stevanovic, O.D., Licina, B.Z., Radojevic, I. D., \& Comic, L.R. (2012). Biological Activities of exctracts krom cultivated Granadilla Passiflora alata. EXCLI Journal ;11:208-211.

[15] Suheiry, W., and Anggraini N. (2016) 'Formulation and evaluation of Peel-off Gel Masks from red rice bran extract with various kind of bases', International Journal of PharmTech Research, 9 (12), pp. 574-580.

[16] Vieira, R et al. (2009) 'Physical and physicochemical stability evaluation of cosmetic formulations containing soybean extract fermented by Bifidobacterium animalis', Brazilian Journal of Pharmaceutical Sciences, 45 (3), pp. 515525.

[17] Garg, A., Aggarwal, D,. Garg, S., dan Sigla A.K., (2002). Spreading of Semisolid Formulation: Pharmaceutical Technology, September 2002. 